Página inicial: 35 - Página Final: 57

Tipo de artículo: Investigación.

\title{
Pedagogía y territorio. La experiencia de la Escuela de Derechos Humanos y ciudadanía en el Bajo Cauca Antioqueño.i
}

\author{
Pedagogy and Territory \\ The Experience of the School of Human Rights and Citizenship in the Bajo Cauca \\ Region in Antioquia.
}

\author{
Por: Yeny Pino Franco ${ }^{1}$, David Sánchez Calle ${ }^{2}$
}

Recibido: junio de 2016 Revisado: noviembre de 2016 Aceptado: noviembre de 2016

\section{Resumen.}

La Escuela de DDHH y Ciudadanía (EDHC), surge como respuesta a las exigencias de las comunidades campesinas en el paro agrario nacional desarrollado en el 2013 (Colombia), donde se visibilizaron territorios con sistemáticas violaciones a los Derechos Humanos, infracciones del Derecho Internacional Humanitario y la falta de diálogo entre Estado y ciudadanía. En este sentido, esta experiencia de formación, cobra especial importancia para el reconocimiento del conflicto, el conflicto armado, el contexto y la diversidad social en los territorios. bases para la construcción colectiva de Paz y de sociedad.

Palabras clave. Formación popular, territorio, resistencia civil, autonomía, comunidades organizadas, conflicto armado, exclusión social.

\begin{abstract}
.
The School of Human Rights and Citizenship (EDHC), appears as an answer to the demands of peasant communities during the national agricultural strike, which took place in Colombia in 2013. In it, it was evident to appreciate systematic violations of the Human Rights in the territory, infringement of the International Humanitarian Right and the lack of dialog between the State and the citizens. In this sense, this experience of training becomes important for the recognition of the conflict, the armed conflict, the context, and the social diversity in the territories, which are the foundations for the collective construction of Peace and society.
\end{abstract}

Key words: Popular Training, Territory, Civil Resistance, Autonomy, Organized Communities, Armed Conflict, and Social Exclusion.

\footnotetext{
1 Socióloga, integrante del grupo de investigación Kavilando y la Red Interuniversitaria por la Paz (Redipaz) Medellín (Colombia). Grupo de Estudios, Acuerdos de la Habana. Kavilando. Contacto: ypino2015@gmail.com

2 Politólogo, integrante grupo de investigación Kavilando, Grupo de Estudios acuerdos de la Habana. Kavilando, e integrante de la Red Interuniversitaria por la Paz (Redipaz) Medellín (Colombia). Contacto: dsanchec@gmail.com
} 


\section{Introducción.}

La sociedad colombiana se viene configurando con las múltiples situaciones que acontecen en los territorios en el campo económico, político, cultural y social que hace difícil enmarcarla. Acontecen situaciones que se salen de los códigos penales, de los ideales-tipo de las sociologías, de los diez mandamientos cristianos, y demás formas de explicación que ha desarrollado la humanidad con tanto esfuerzo y dedicación.

En cada uno de los territorios, se establecen dinámicas propias donde se combina lo autóctono con lo nuevo, generándose situaciones inesperadas y en algunos casos paradójicas. Lo que se evidencia en la fotografía de Puerto López (fotografía 1), es una de ellas. Para algunos, es imposible la hermandad entre estos grupos armados, por su diferencia ideológica, pero resulta que en los municipios muchos de estos personajes que protagonizan la guerra hoy, en uno u otro bando, son familiares y hermanos, tíos, amigos, parejas, hijos que terminan en diferentes grupos legales o ilegales, y enfrentados a muerte. Desde una mirada externa al territorio se puede ver absurdo este llamado, pero desde el contexto es un llamado legítimo a sus familiares y amigos, siendo un pequeño ejemplo de las complejidades de nuestra configuración como sociedad en medio de la guerra.

Foto 1: Puerto López

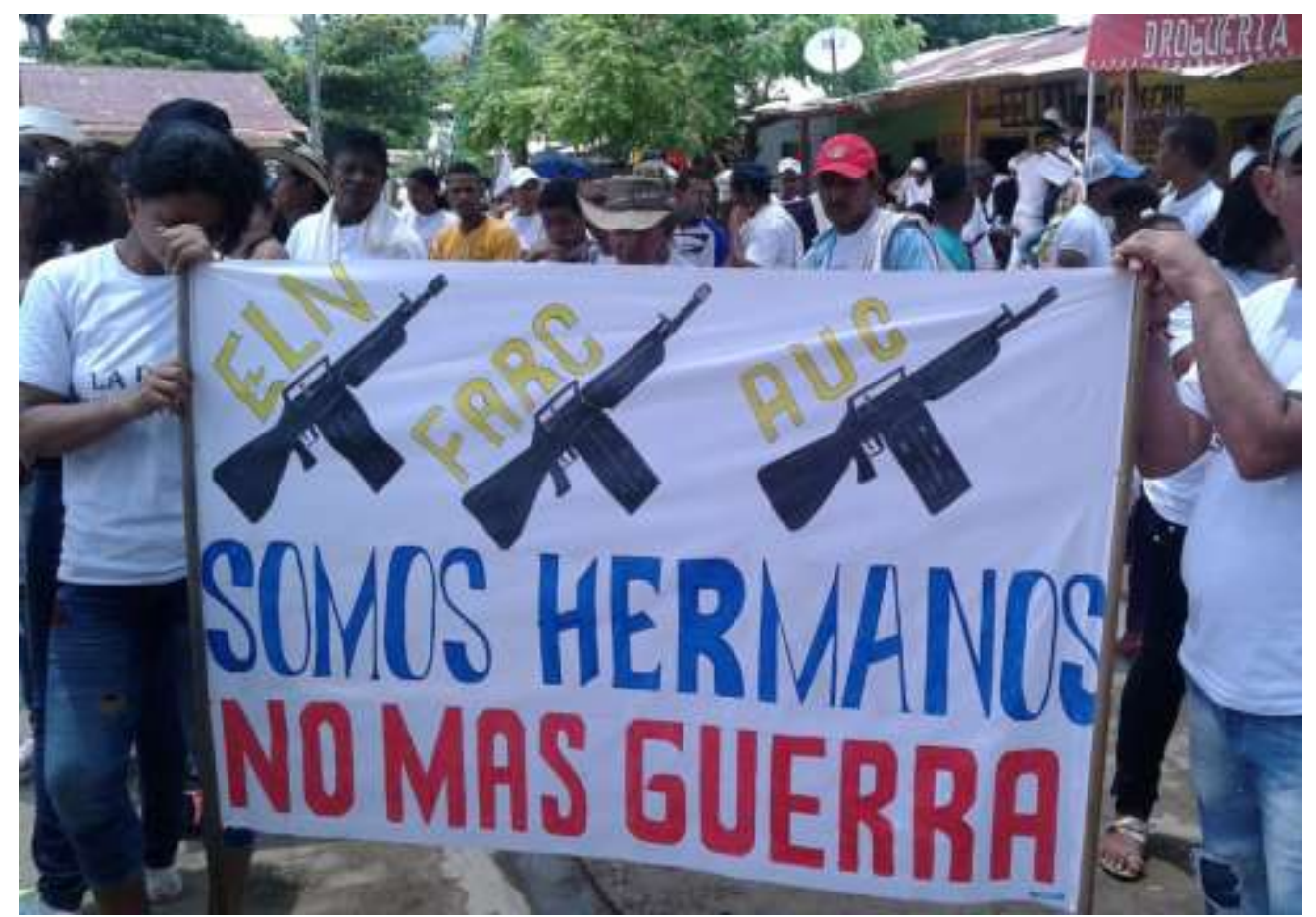

Fuente: propia - Puerto López. Municipio de El Bagre.

Otra situación ejemplificante, es lo que acontece con los grupos armados legales en regiones como estas, han perdido legitimidad y poder por sus prácticas corruptas y violatoria de los DDHH, (siendo paradójicamente la defensa del ser humano, sus derechos y su integridad su función principal). Vemos que el poder legítimo, hasta para la solución de conflictos de pareja, 
son los grupos armados ilegales, guerrillas o paramilitares, y las administraciones públicas son un decorado más de los pueblos.

En términos generales, la gente expresa temerle más a la fuerza pública que a los grupos ilegales, y ven en las administraciones, (que deben hacer justicia), una "partida de ladrones y corruptos".

Cada región del país le viene poniendo su ingrediente particular a la configuración nacional; múltiples estrategias de sobrevivencia y resistencia de la gente que día a día vive la guerra, a través de acciones legales o nuevas acciones que surgen de las necesidades, en un escenario de agudización permanente de las precariedades económicas de las mayorías.

La Escuela de DDHH y Ciudadanía (EDHC), surge en algunas de las subregiones de Antioquia como respuesta a una de estas necesidades. En el año 2013 el paro agrario nacional hace evidente, para todo el país, unos territorios con sistemáticas violaciones de los Derechos Humanos, infracciones del Derecho Internacional Humanitario y la falta de diálogo entre Estado y ciudadanía; a raíz de este acontecimiento en el departamento de Antioquia se construyen unos acuerdos entre las organizaciones campesinas y la gobernación de Antioquia, entre ellos, el desarrollo de un proceso de formación en DDHH para los líderes y sus comunidades.

En este ejercicio de escuela de Derechos Humanos (DDHH), desarrollado en el 2015, dialogamos y reflexionamos, permanentemente, con los integrantes de la escuela su día a día desde el territorio y con una metodología de formación popular.

Presidentes o presidentas de las JAC de los municipios, líderes de asociaciones campesinas, afros, de mujeres, entre otras; todas víctimas del conflicto armado. Cada uno protagonista de diversas historias acontecidas y aconteciendo, algunas más trágicas y aterradoras que las otras, a veces, con la sensación de ser historias surrealistas, por la forma absurda, horrorosa y paradójica con que se presentan.

De esta manera, este texto pretende relatar esta experiencia vivida de escuela de formación en DDHH y contexto de conflicto armado; cómo se fueron implicando estos dos espacios, los comportamientos y los conflictos que surgieron al interior, las historias que se iban relatando en las sesiones sobre la configuración del territorio y la cotidianidad, y esto cómo iba definiendo el quehacer de la escuela de DDHH.

\section{Metodología.}

La sistematización como proceso metodológico, tiene además diferentes respaldos epistemológicos, y por tanto distintos enfoques. Según Ghiso (2001), los diferentes enfoques de sistematización son producto de "clausuras teórico-prácticas"; que, no obstante, tienen entre ellos "hibridaciones" y están determinados asimismo por la diversidad de sujetos, lógicas y racionalidades, culturas y discursos. Estos enfoques son:

Histórico- Dialéctico: las experiencias hacen parte de una práctica social e histórica, dinámica, compleja y contradictoria, que puede leerse y comprenderse de manera dialéctica en tanto son ricas y contradictoras. Prácticas que están en relación con otras similares en contextos que permiten explicarlas. 
Dialógico e Interactivo: experiencias como espacios de interacción, comunicación y relación, se pueden leer desde el lenguaje y desde las relaciones contextualizadas. Desde este enfoque se construye conocimientos a partir de referentes externos e internos que permiten tematizar problemas que se dan en las prácticas sociales.

Deconstructivo: la sistematización como una intervención que permite entrar en la voz, en la autoconciencia de lo institucional y los imaginarios y en los campos institucionalizados donde se ejerce poder. Se construye conocimiento al reconocer las huellas que dejan la acción y los orígenes de la misma.

Reflexividad y construcción de la experiencia humana: asumen la implícita epistemología de la práctica, basada en la observación y el análisis de los problemas que no tiene cabida en cuerpos teóricos aprendidos o aplicados. La sistematización se vincula a la resolución de problemas permitiendo hacer frente a desafíos del contexto.

Hermenéutico: la sistematización es una labor interpretativa de los sujetos de la práctica, develando intencionalidades, sentidos y dinámicas para reconstruir las relaciones entre sujetos sociales de la práctica para dar cuenta de la densidad cultural de la experiencia.

Histórico Hermenéutico: un enfoque que desde una perspectiva comprensiva privilegia la comprensión, significatividad y la relevancia cultural de los sujetos y sus prácticas. Pretende comprender los significados, sentidos, acciones y discursos de los sujetos para entender las lógicas e interpretaciones de las relaciones sociales en las prácticas. Teóricamente la fenomenológica y el interaccionismo simbólico referencia este enfoque histórico hermenéutico (Ruiz Botero, 2002).

De acuerdo con la presente propuesta, consideramos que el enfoque dialógico e interactivo es el más adecuado para orientar el proceso de sistematización, ya que tiene como eje articulador la voz y capacidad de las personas para transformar su realidad, revindicar sus derechos e intervenir sobre el desarrollo y bienestar que necesitan en sus territorios.

En el enfoque dialógico las experiencias "son entendidas como espacios de interacción, comunicación y de relación", escenarios que serán promovidos en el proyecto bajo el interés de promover la participación, comunicación y retroalimentación de saberes de los actores sociales, institucionales políticos y económicos que habitan, ordenan e intervienen el territorio. Espacios que nos permiten leer esta experiencia "desde el lenguaje que se habla y en las relaciones sociales que se establecen en estos contextos” (Ruiz Botero, 2002); Así mismo, este enfoque plantea como punto central construir conocimiento a partir de los referentes externos e internos que facilitan tematizar las áreas problemáticas, expresadas en los procesos conversacionales que se dan en toda práctica social (Ghiso A. , Sistematizacion de experiencias en Educacion popular, 2001), metodología sobre la que se estructurará y validarán las acciones y actividades sugeridas en la ruta metodológica para el presente escrito.

Este enfoque entonces parte de reconocer toda acción como un espacio dialógico, y relaciona diálogo y contexto, introduciendo en el proceso de reconstrucción de la experiencia elementos estructurales claves, tensiones e intereses entre los actores, el problema del poder y las particularidades de los contextos, reconociendo los elementos que organizan, coordinan y 
condicionan la interacción. De esta manera, el enfoque dialógico implica la caracterización y dinamización de categorías de análisis que describen contextos, actores, y elementos estructurales en diversas dimensiones de tipo político-económico-social-ambiental y cultural que caracterizan la experiencia a sistematizar. (Ghiso A. , 1999); (Torres Carrillo, 1998)

\section{La escuela de DDHH y ciudadanía.}

La escuela de DDHH se concibe como un proceso de formación de líderes y dirigentes comunitarios, cuyos objetivos ha sido dialogar temas como: DDHH y DIH, funcionamiento del estado, mecanismos de participación, memoria histórica, democracia, violencia, economía, paz y justicia, entre otros, del contexto local y nacional en los territorios. (Universidad Católicia del Norte, 2015)

La escuela busca crear un espacio para que las distintas organizaciones sociales que viven en medio del conflicto armado, social y político se reconozcan en su trabajo (con avances y retrocesos), se fortalezcan y creen lazos de unidad frente a las acciones de cada colectivo; porque "el juntarnos nos permite volver a soñar, quitar el miedo y eliminar estigmas, para construir un modo de habitar el territorio acorde con nuestras necesidades e intereses" (Comunidad Bajo Cauca, 2015).

"El 4 de marzo de 2015, en el municipio de Ituango, un hecho que sin duda marcó la diferencia en la historia de ese municipio; se realizó el lanzamiento oficial de la escuela de Derechos Humanos para el departamento de Antioquia. Con 16 formadores que se tienen para apoyar los procesos formativos, se abrieron 8 sedes ubicadas en los municipios de Ituango, Tarazá, San Andrés de Cuerquia, Yarumal, Liborina, Anorí, Bagre y Peque, en las que suman 265 participantes, entre ellos contamos con los líderes de los municipios, líderes indígenas, funcionarios públicos y comunidad en general." (Universidad Católicia del Norte, 2015)

La estrategia Pedagógica se ha sustentado en metodologías y didácticas vivenciales proporcionadas desde la educación popular y pedagogías críticas. En las que no se descarta lo cognitivo, pero en donde se apuesta de igual forma por lo sentimental y emocional, como caminos para el cambio de actitud y de relacionarnos entre nosotros. La escuela supera un proceso educativo tradicionalista, de charlas magistrales, que no vincula a los participantes, abstraído de sus necesidades, del conocimiento de la realidad concreta y de la acción organizativa dentro de los territorios con sus dinámicas particulares, para transformar dicha realidad, mediante estrategias de educación, investigación, agenciamiento social e institucional y difusión masiva. (Ghiso, 2016)

A partir de allí, se genera conciencia social en cada uno de los participantes; se busca superar el asistencialismo del estado y las ONGs que ha generado tanto daño a las iniciativas populares y la autonomía en el trabajo; el reconocimiento, respeto y construcción con el otro a partir de la diversidad y las diferencias; todo esto como bases fundamentales para construir unas relaciones humanas y democráticas que son las que necesita cualquier grupo social para que se dé una verdadera cohesión.

Es por ello, que la escuela de DDHH y las personas que la asuman, no se apartan del contexto que lo circunda, eso que pasa "afuera" es el sentido de la existencia de la misma, es la materia prima y es determinante en su dinámica interna. La escuela debe tener la flexibilidad y sensibilidad para dejarse guiar por lo que demandan las situaciones "externas", entender y lograr 
introducir constantemente ese acontecer en sus reflexiones, en su quehacer pedagógico y político, y en la dinámica del grupo, si quiere ser un proceso de formación y transformación de seres humanos.

La apuesta es entonces por aportar a las organizaciones campesinas, de mujeres, afros, indígenas entre otras, contenidos y metodologías, en tanto apoyar sus procesos y ser dinamizador de conocimientos, para que ello sea multiplicado en los barrios, veredas, colegios etc., teniendo como protagonistas a quienes participaron de la misma.

\section{La experiencia del bajo cauca.}

Mapa 1: Región del Bajo Cauca (Antioquia-Colombia)

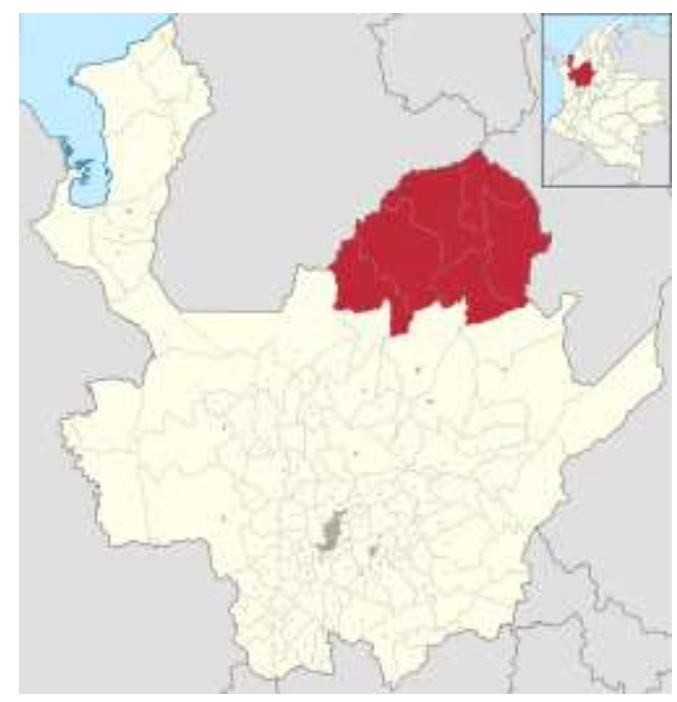

Fuente: https://es.wikipedia.org/wiki/Bajo_Cauca

La escuela de Derechos humanos y Ciudadanía, se trabajó durante 10 sesiones de 13 horas cada una, cada 15 días (sábados y domingos) durante cuatro meses aproximadamente; las sesiones se realizaron en este orden (Tabla: 1) y cada uno de los facilitadores tenía el hilo conductor que se planteó desde los participantes, según sus necesidades y visiones sobre el territorio.

Tabla 1: Temas tratados en la Escuela de Derechos Humanos y ciudadanía.

- Cartografía personal y social en derechos humanos

- Proyecto de Investigación Acción Participativa en derechos humanos y ciudadanía

- Enfoque diferencial y su aplicación en el contexto

- Estado social de derecho, democracia y derechos fundamentales 
- Fundamentos básicos de derechos humanos y derecho internacional humanitario

- Mecanismos formales y no formales de participación ciudadana

- Mecanismos e instancias de protección de derechos humanos

- Políticas públicas en derechos humanos y ciudadanía

- Memoria histórica, paz y reconciliación

- Pedagogía para la paz y los derechos humanos

Fuente: Elaboración propia

La escuela del Bajo Cauca fue la experiencia de la unión de dos sedes de la escuela, la Escuela de Tarazá y la Escuela de El Bagre, que buscó un proceso de reconocimiento colectivo de las organizaciones presentes en esta Subregión (Tarazá informa, 2015); poblaciones que tienen en común las historias de conflicto armado y social, la estigmatización de la subregión, la economía del oro y la coca, el desplazamiento forzado, entre otros, y que tienen en sus manos el sueño y el deseo de construir un futuro diferente a su trágico presente.

En el Bajo Cauca, casi todos los días hay asuntos de vulneración de los DDHH, desde el carente acceso a salud, educación, cerramiento de los espacios de participación e incidencia política, limitación en la movilidad, hasta el asesinato, el desplazamiento forzado, desalojos de familias, minas anti personas etc. Estas prácticas se vienen dando hace más de 20 años, siendo esta la región que hoy presenta la tasa más alta de homicidios del departamento. (Instituto Popular de Capacitación, 2015)

En esta subregión hay una clara estigmatización al tema de $\mathrm{DDHH}$, prohibiendo incluso hablar de ello y quien lo haga, es calificado de guerrillero, por ello, aunque hubo mucha expectativa de la población por entrar en el espacio de la escuela, se sentía el temor. (Botero Fernandez, 2016)

\section{Población diversa.}

Para construir la escuela de DDHH en el territorio se comenzó por el reconocimiento de los espacios, sus dinámicas y los grupos o personas que podrían ser invitados a la misma; se convocó a asociaciones campesinas, juntas de acción comunal, diversos resguardos indígenas y consejos comunitarios afros, asociaciones de mujeres, asociaciones mineras, concejales, personas con discapacidad, personas adultas mayores, funcionarios públicos, profesores jubilados, jóvenes, estudiantes de bachillerato, representantes LGBTI, trabajadores y trabajadoras, personas que no pertenecían a organizaciones sociales, pero que tenían un claro liderazgo en sus barrios y veredas, y que llegaron al espacio producto de las visitas que se hicieron en distintos lugares de la subregión. (Universidad Católicia del Norte, 2015) \& (Universidad Católica del Norte, 2016) 
Si bien este espacio de la escuela es amplio y permite todas las opiniones políticas, el contexto de miedo y "disciplinamiento social", efecto de la aplicación de la "pedagogía del terror" que encontramos en el Bajo Cauca por la violencia vivida, un reflejo de lo vivido en todo el territorio nacional, limitaba las posibilidades de expresión abierta, desde la escuela se proponía construir un escenario donde hubiera libertad de expresión de los participantes, sin embargo, estos expresaban miedo de manera constante y se autocensuraban para tratar algunos temas.

En esta lógica, bien vale resaltar que, una de las situaciones que empezó a evidenciar las particularidades del conflicto en la región fue que en la sede de El Bagre no hubo posibilidad de encontrar integrantes de la población LGBTI, organizados o no, que pudiera asistir a la escuela, la razón que la gente expresaba era que no existían en este territorio, puesto que habían sido desplazados con amenazas, intimidaciones y asesinatos por parte de todos los actores armados durante muchos años y terminaron por dispersarse y esconderse.

De igual forma, en la comunidad indígena de la vereda El 90, en el municipio del Bagre, por ejemplo, la guerrilla obligó a los pobladores a exigir a la administración municipal una carretera que beneficiaría a los indígenas, pero les dijeron que, si no les respondían, ellos (los indígenas) la tenían que hacer, a lo que la gente expresaba "pues hay que hacerlo". Se evidencia así en las personas un asentimiento consciente e inconsciente a toda orden o directriz que se les dé. (Es de destacar que hay organización indígena desde 1998, en el 2003 fueron reconocidos por el estado y en el 2013 a una comunidad de diez familias les dieron 172 hectáreas.)

\section{Economía.}

En lo que toca a los aspectos económicos de la región, es de resaltar que: "el campesinado de la zona ha pasado por crisis económicas y falta de oportunidades sociales y económicas que los ha llevado a subsistir de la coca y la minería y, por ende, a asumir las consecuencias de las fumigaciones, erradicaciones, judicialización y criminalización de la protestas" (Comunidad Bajo Cauca, 2015), estas últimas siendo el mecanismo más usado por los campesinos para exigir sus derechos.

Según los participantes de la escuela: "cuando el oro se desgastó, vino una hojita a resolvernos la economía y todos terminamos migrando hacia allá” (Comunidad Bajo Cauca, 2015), y de la mano de esta hoja de coca se dieron nuevas dinámicas en la región como la aparición y consolidación de los grupos paramilitares, a mediados de los años 90.

\section{Control Paramilitar.}

Los grupos paramilitares terminaron acaparando toda la cadena de distribución de la base de coca, obligaron a los campesinos a aceptar el precio que ellos ponían y ellos decían a quien se podía vender el producto, lo que llevó a la quiebra nuevamente al campesinado, debiendo dejar este, en gran medida, la siembra de hoja de coca, además de las constantes violencias ejercidas 
por los grupos armados hacia los campesinos y los habitantes de los cascos urbanos. (Balbin Alvarez, Insuasty Rodriguez, Cadavid Acevedo, \& Restrepo Marín, 2009)

Para hacerse al poder de la región, realizaron diversas masacres en cada lugar del territorio quedándose efectivamente con el control militar, económico y político. Hoy, luego de la “desmovilización de los grupos paramilitares" en el 2005 por medio de la Ley de Justicia y Paz, hoy se puede constatar, que estas estructuras siguen ejerciendo control en la región. (Instituto Popular de Capacitacion, 2012)

Como en las dictaduras del cono sur, prohibieron las asociaciones en el territorio, prohibieron las reuniones de más de tres personas, las Juntas de Acción Comunal fueron rotundamente prohibidas, fueron asesinados todos los presidentes y líderes que insistieran en su continuidad.

Con este contexto, cuando se habla de "disciplinamiento social" y de "pedagogía del terror" se hace referencia a la configuración mental y social de los pobladores de la subregión puesto que, Las dinámicas del conflicto armado rompieron los lazos comunitarios e instalaron unos comportamientos en las personas de obediencia, donde se dan incluso, situaciones que atentan contra la dignidad individual y del grupo.

Por medio de la violencia desatada hacia las poblaciones, se creó un miedo tan profundo al otro, que con un poco de autoridad o de poder, se puede dominarse fácilmente y doblegar los intereses a la imposición de los que tienen el poder.

\section{Sentimientos a los que se hace frente en el proceso de formación.}

Por lo rápidamente planteado anteriormente, se pueden deducir estos sentimientos que se evidenciaron en el interior de los grupos, a partir de juntarnos para hablar de Derechos Humanos, en este contexto de conflicto social y armado latente:

Desconfianza: La composición de los grupos, su diversidad y por supuesto, el pertenecer a diferentes municipios de la región, generaba inicialmente la necesidad de cuidar lo que se dice,

quién lo dice y de donde viene quien lo dice. Esto, se fue superando con el avance de cada sesión, hasta el punto de cohesión, reconocimiento y respeto entre los participantes.

Miedo: Existía miedo a mencionar sus historias, a contar las historias de la región y por supuesto a escuchar las historias de otros. La estigmatización de cada uno de los territorios imponía estar en silencio, en contraste con el deseo de conocer nuevas personas, configuraba un interesante inicio.

\section{Descripción del proceso y sus vivencias.}


Frente a esta realidad, la primera sesión de la escuela promovía un desacomodo personal, una relectura de cada individuo que a su vez puso la piedra base para romper las barreras mentales y codificaciones culturales de los participantes. Los participantes se encontraron con el enfoque de construcción colectiva de conocimiento que proponía la Escuela, nuevo para ellos en su propuesta y en la aplicación en su contexto. Aunque generó un poco de resistencia al principio, luego de la explicación de las dinámicas vivenciales y de las primeras reflexiones, se fue generando otra dinámica dentro del grupo. Ellos manifestaron estar acostumbrados a la estrategia de la educación tradicional donde el profesor "nos llena el tablero de leyes y de normas que debemos aprender a aplicar"; sin embargo, esto fue un choque que superaron rápidamente puesto que, como lo manifestaron: "acá nosotros somos los que llevamos la propuesta y nos conversamos desde nuestra propia realidad".

En la sesión de cartografía social se les propuso trabajar en parejas para realizar distintos ejercicios, entre ellos juntar las caderas, y a pesar de su desconcierto todos lo realizaron, al ser cuestionados de porqué lo hacían si no se sentían cómodos decían: "porque ustedes lo ordenan y si queremos estar en este proceso debemos hacer lo que ustedes digan”.

La sesión de Investigación Acción Participación, aterrizó al grupo y le abrió una ruta de trabajo nueva que los convocó y comprometió aún más con el proceso, los movió a realizar acciones de intervención directa sobre el territorio y con sus habitantes y les propuso indagar sobre sus realidades y las rutas de transformación posible para sus necesidades y reclamos. Se logró cohesión con los trabajos en grupo y la presentación de intereses de cada participante y la organización que representaban, en cuanto a temas de interés.

El tema de "enfoque diferencial aplicado en contexto", fue un tema novedoso para las organizaciones sociales y en la reflexión nos permitió develar que el Bajo Cauca Antioqueño es particularmente diverso, encontramos allí comunidades indígenas, negros, LGBTI, campesinos, mineros, víctimas del conflicto social y armado, grupos de mujeres, la mayoría víctimas de la violencia de género y grupos de discapacitados, cada uno con una cultura y una forma particular de relacionarse con su entorno, y paradójicamente, en esta región, encontramos también la incivilización, la intolerancia y la discriminación de estos grupos sociales y sus necesidades, por parte de todos los actores armados e institucionales.

Ejemplo de ello, ha sido el largo periodo que vivieron las comunidades indígenas sin ser reconocidas en su diferencia étnica en el municipio de Cáceres, lo que ha significado una discriminación con este grupo socialy étnico. Otro asunto particular de esta región ha sido el desplazamiento y asesinato de personas pertenecientes a la comunidad LGBTI, en actos de intolerancia, al igual que los casos de violencia y asesinatos de mujeres que se agudizaron en el segundo semestre del año 2015. 
Foto 2: Sesiones de trabajo.

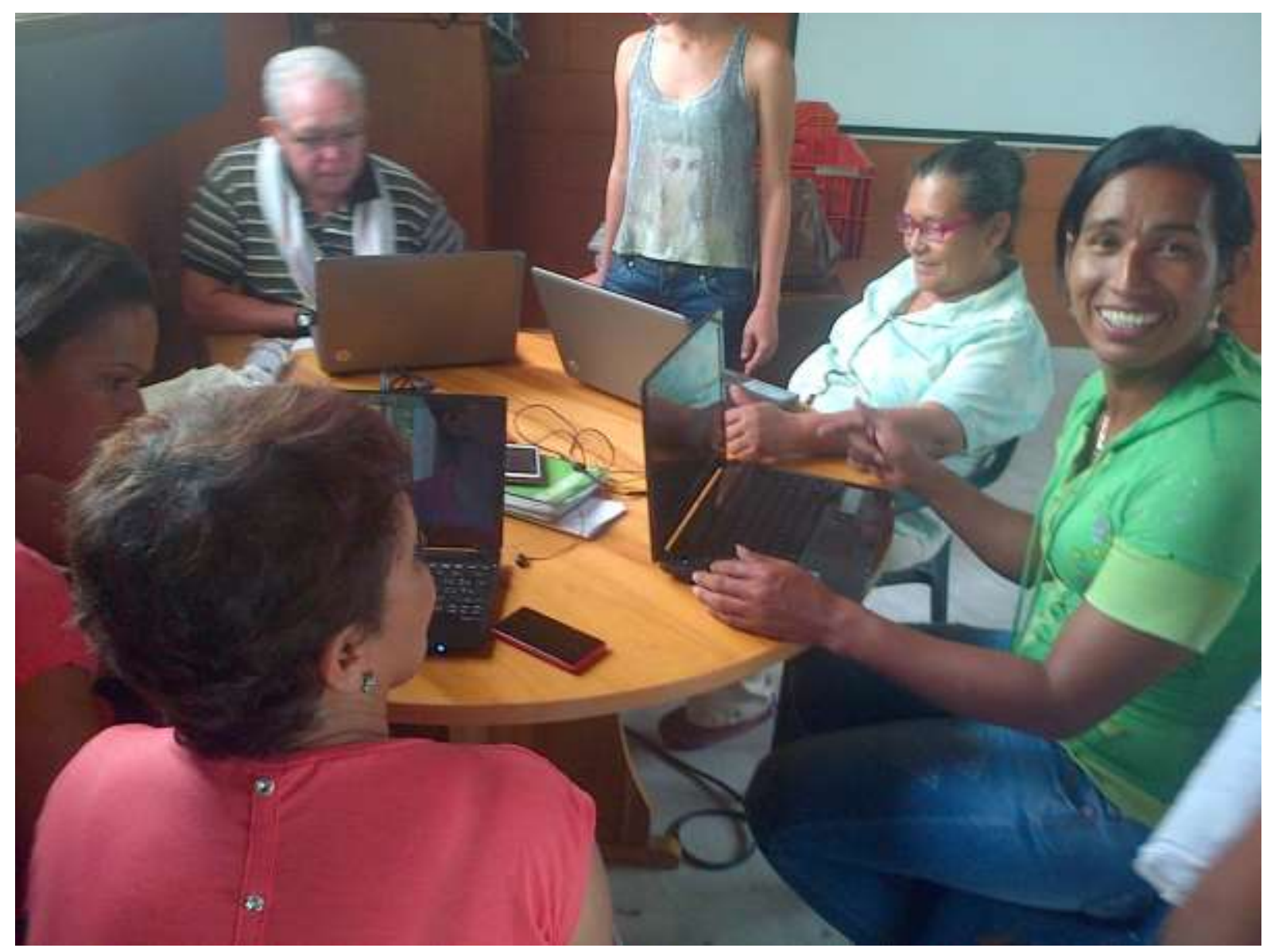

Fuente: Archivo del proceso.

Si bien es un tema fundamental para la zona, ya que las organizaciones han vivido permanentes exclusiones y poco se ha reconocido la multiculturalidad y diversidad de estas, ha sido ajeno a sus reivindicaciones. A partir de aquí, la escuela les propone sumar a las lecturas del territorio este componente para las realidades políticas y sociales específicas y parte de las agendas de las organizaciones sociales y entidades públicas.

En la sesión 4 de "Estado Social de Derecho, Democracia y Derechos Fundamentales", la situación más preponderante a rescatar fue la intención que asumieron los participantes para generar debates respetuosos. Se merma la barrera del miedo y la desconfianza que estaba presente en las sesiones anteriores, porque se da un tema en el que ellos pudieron participar abiertamente, es decir, se diseñó el taller de tal manera que fueran los participantes quienes dinamizan las discusiones a partir de sus conocimientos y, porque no, creencias alrededor de los temas propuestos. 
Además, el trabajo en equipo va tomando fuerza para la resolución de actividades. Para este momento contamos con unos grupos más dispuesto y sólidos con respecto a la metodología de la educación popular.

En la sesión de "Mecanismos formales y no formales de participación", el grupo ha alcanzado un avance interesante en cuanto a cohesión grupal, solidaridad y reconocimiento del otro, además las discusiones que se están generando ya tienen una asimilación teórica y práctica de sus realidades, de su historia y de su porvenir. Evidenciamos además como se están cuestionando desde el punto de vista político, el papel de sus organizaciones y entidades, y como se entienden, sin tantos prejuicios y discriminaciones las luchas en otros territorios y de otros sectores distintos al suyo.

Tenemos entonces, un grupo más abierto a discusiones, siempre desde el respeto al otro, se va poco a poco construyendo un espacio propicio para ejercer el derecho a controvertir sin el miedo reinante en el contexto de la zona, por fuera de la escuela.

La última sesión correspondiente a la construcción de pedagogías para la paz tuvo una fuerte influencia en lo que podríamos considerar el cierre de un ciclo del proceso formativo puesto que generó inquietudes en las personas en tanto debían revisar su configuración cultural, el modelo de vida y de actuar que nos hemos venido formando alrededor del conflicto, de nuestros intereses, de nuestro territorio, posición en la sociedad. Las personas logran ver la dualidad de seres que nos habitan y reflexionan alrededor de sus comportamientos frente al otro y a lo otro.

\section{Dificultades en el proceso.}

En términos del proceso formativo, como dificultades se vio la poca motivación de la mayoría de los asistentes para indagar más allá de los elementos que se nos dan en la escuela.

Los y las participantes tenían un papel pasivo a la hora de profundizar en los temas que les compartían los facilitadores de la escuela esto dado que la gente aún está acostumbrada a la forma de educación tradicional, que todo se lo daban en el aula de clases y desde allí les decían que tenían que hacer. Desde la escuela hubo una insistencia y motivación permanente porque cada uno aportara activamente al grupo tanto en el desarrollo de las sesiones, como en las investigaciones, los debates o cualquiera actividad que propusiéramos.

Desde un inicio entre todos pusimos las reglas de convivencia, las expectativas, nos hacíamos las críticas para mejorar el trabajo, esto nos daba la idea que la escuela éramos todos y funcionaría en la medida que nos pusiéramos de acuerdo y diéramos nuestra dinámica como grupo.

Logramos que la mayoría legitimara estas normas de convivencia lo que permitió un ejercicio de democracia dentro del aula de clase, sin embargo, un participante hacía la reflexión de que el comportamiento democrático y respetuoso que se dio dentro de las sesiones de la escuela no correspondía a la realidad por fuera de ella para los participantes; Él planteaba que el respeto se 
daba porque si estábamos trabajando los DDHH debemos ser coherentes con respetar los DDHH de los compañeros, la realidad por fuera de este espacio de formación era intolerante y violenta.

¿Qué pasa entonces con esas personas por fuera de la escuela? ¿Cuál es su comportamiento en la cotidianidad?

Los líderes están en varias actividades, debido a la múltiple oferta institucional de formación en cursos de DDHH y otros temas en las regiones, lo que no permiten que la gente se concentre en un sólo proyecto y terminan de manera mecánica respondiendo a todos estos asuntos y no transformando su realidad.

Frente a la iniciativa de indagar sobre la memoria histórica encontramos algunas dificultades en el Bajo Cauca. Los integrantes manifestaron la poca información disponible sobre la historia del conflicto en los municipios, y la dificultad para recopilar historia oral por el contexto de conflicto armado actual. También se planteó que los procesos que se están dando en formación en memoria histórica no están dando los elementos suficientes para hacer memoria histórica, y lo máximo que logran es memoria.

A partir de los ejercicios de análisis de coyuntura que hacíamos en cada sesión, vimos con preocupación cómo el contexto del Bajo Cauca viene complejizando, avizorando una crisis humanitaria. Esto hace que aumente el miedo a expresar ideas, la organización social y se tema a la defensa de los DDHH.

Y ante este panorama un conformismo por parte de los pobladores y vecinos que ya no genera indignación, aunque podríamos también decir que hay una indiferencia obligada producto de la constante intimidación y amenazas a los líderes comunitarios. Intimidaciones permanentes a los individuos, a los líderes, a las comunidades por parte de actores institucionales, insurgencias, megaproyectos, fuerzas armadas, paramilitares; desde la amenaza directa hasta el control de las costumbres (horarios, lugares, movilidad). 
Foto 3: Ejercicios grupales - individuales

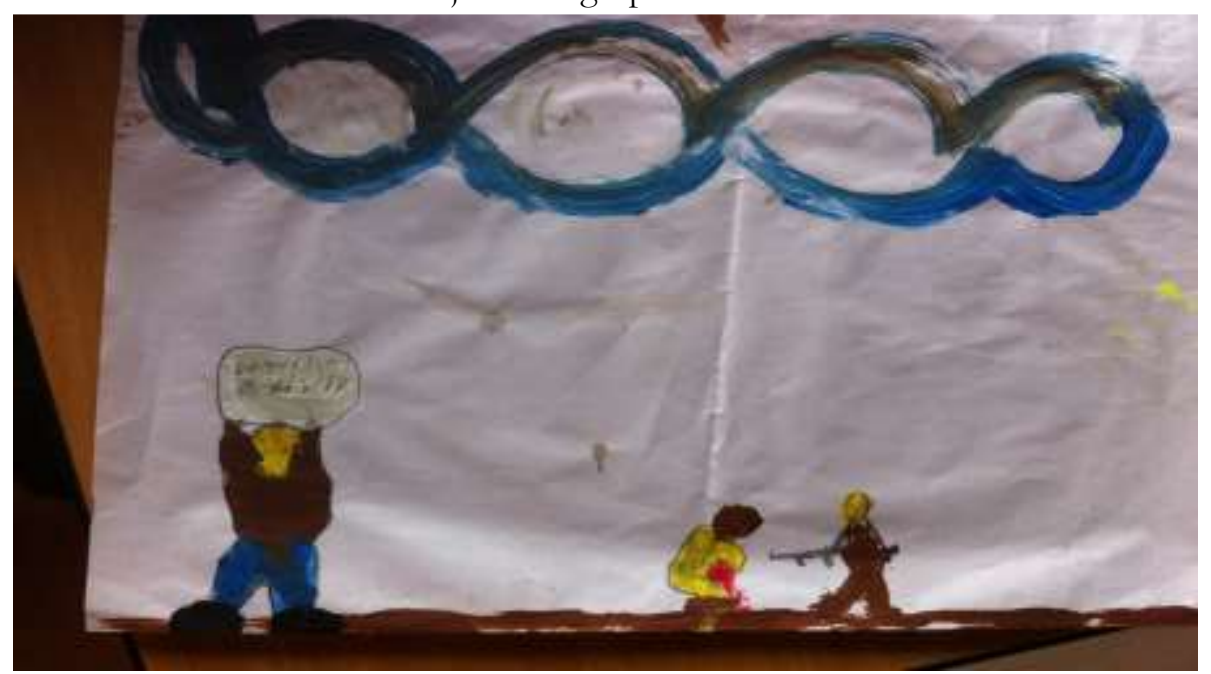

Fuente: Archivos del proceso.

\section{Las historias de la transformación en el territorio. Más allá de la Escuela.}

Consecuentes con la estrategia de difusión propuesta desde el proceso de la escuela y dentro de la lectura específica del contexto, las dinámicas propias de la región y las realidades de cada colectivo en la subregión, nos propusimos con los participantes encontrar estrategias que permitieran ingresar a las comunidades sin generar choque con las personas, ni con los poderes presentes y que dominan la subregión. En este sentido, encontramos en distintas actividades como el cine, escuelas de formación campesina en las veredas y corregimientos, intercambios entre organizaciones, diálogos de saberes entre grupos étnicos y las organizaciones campesinas, foros con funcionarios públicos etc., formas de lograr un encuentro entre y con las comunidades para conversar desde las propias veredas y barrios sus intereses y vulneraciones.

Por ejemplo, en la Vereda El 90, del municipio de El Bagre, estuvimos realizando una actividad comunitaria, llegamos hasta aquí por invitación del Cacique de la comunidad indígena quien es participante de la escuela y estaba interesado en poder conversar con la comunidad y presentarle el proceso de formación; además de poder conversar con otras organizaciones como en este caso, campesinas y afro del mismo municipio, y por supuesto, las experiencias de la escuela de Tarazá. Igual sucedió en el municipio de Cáceres en el corregimiento de San Pablo, durante tres días estuvimos realizando un proceso de formación en DDHH y democracia para campesinos a partir de la metodología de la educación popular, con adultos y niños, dialogando con ellos sus situaciones particulares y construyendo propuestas.

Otras historias con que nos encontramos en la escuela y la región fueron las de los indígenas Zenúes, los cuales llegaron al Bajo Cauca por razón del desplazamiento forzado del departamento de Córdoba; ellos se ven como unos sobrevivientes de la guerra y la discriminación. 
Los Zenúes por estar en territorio Antioqueño, que no es su lugar de origen, no han sido reconocidos por el gobierno nacional, y las administraciones municipales no han hecho gestiones en favor de estas comunidades. Debido a estas situaciones, ellos se han organizado: "luchamos y estamos en la resistencia y tenemos una cultura diferente $(. .$.$) nuestro proceso fue primero$ nosotros mismos reconocernos como indígenas, antes que alguna entidad nos reconociera (...) entre nosotros los indígenas no tenemos discriminación (...) nuestro sueño es llegar mucho más allá, nosotros luchamos por un futuro mejor, con una visión diferente a la de los occidentales". En el año 2000 empezaron a organizarse de manera autónoma y al día de hoy cuentan con escuelas indígenas, una IPS propia, una sede en el municipio de Cáceres y la conformación de las guardias indígenas.

Foto 4: Reuniones líderes indígenas Zenúes.

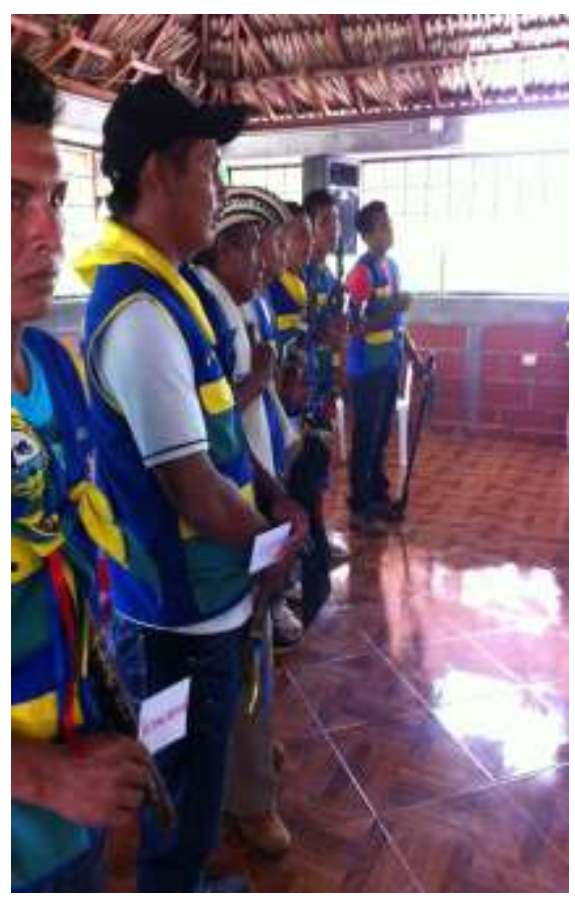

Fuete: Archivo del proceso

Otro ejemplo de construcción desde el territorio es el acaecido en el corregimiento Puerto López, municipio de El Bagre. Como pocas veces en la historia de Colombia un grupo de campesinos le dicen al Estado y a los grupos armados que la paz se construye desde el territorio, desde sus realidades.

El año 2015 fue particularmente convulsionado para los pobladores del corregimiento de Puerto López por las reconfiguraciones del conflicto luego de la desmovilización paramilitar y el reacomodo de sus estructuras, el avance de la guerrilla del ELN y por supuesto la presencia histórica que ha tenido las FARC-EP; además el despliegue de fuerzas militares y de policía, que han tenido una confrontación tensa, y que compromete delitos al Derecho Internacional 
Humanitario como el confinamiento, desplazamientos, atentados a misión médica, etc. y las propias del conflicto como: amenazas, vacunas, intimidaciones, reclutamiento. En este contexto, la comunidad de Puerto López empieza a hacer reflexiones en cómo intervenir esta realidad, cómo decirles a esos grupos armados legales e ilegales que ya están cansados y no quieren más miedo, que su intención es vivir en paz con o sin ellos en su territorio.

\section{Apuestas de Paz y resolución de conflictos, desde abajo.}

Se presentaron así, en los últimos meses, unos hechos que indignaron a la población.

La primera situación fue, la exigencia de pago de vacuna al "chatarrero", un poblador que lleva muchos años recogiendo, vendiendo y comprando chatarra en el casco urbano del corregimiento. "Llegaron unos hombres pertenecientes a un grupo paramilitar y le exigieron pagar $\$ 150.000$ para poder sacar la chatarra hacia El Bagre para ser vendido. A lo cual el "chatarrero" alegó que eso no le daba dinero como para eso y que le era imposible realizar esta labor si debía pagar esa cuantía, que negociaran, pero por supuesto esta gente no aceptó y lo increparon para que abandonara el corregimiento o podría ser asesinado. Entonces, aprovechando su condición y antigüedad en el territorio, se acercó a los líderes y defensores de derechos humanos del territorio y les comento su caso, buscando apoyo y respaldo a su vida y labor. Estos en una acción de valentía se enfrentaron a los paramilitares y les exigieron que explicaran qué sucedió con el "chatarrero". Ellos les indicaron que "las órdenes venían de arriba" y que ellos no podían hacer nada al respecto sino cumplir la orden.

Los habitantes decidieron que este señor no solamente no pagaba la vacuna, sino que tampoco abandonaría el corregimiento y que todo el pueblo asumiría esa decisión. Los paramilitares quedaron de comentarlo con sus superiores y que pronto tendrían alguna respuesta a la situación” (Comunidad Bajo Cauca, 2015). Allí se configuró entonces el primer encuentro, o desencuentro con este grupo.

El segundo hecho y que fue lo que motivó a que se conformará la primera comisión de líderes en defensa del territorio y la paz a favor de las poblaciones afectadas por la guerra, "proceso de defensa del territorio y la vida", fue el asesinato de una joven por el hecho de tener una relación sentimental con un soldado. Por lo cual era acusada de ser "sapa" o infiltrada y de pasar información para que se desarrollaran operativos en el área.

Además, se dieron múltiples asesinatos de moto taxistas, arrieros, barqueros, barequeros, mujeres, jóvenes, todos acusados de ser de un bando o de otro, o simplemente justificados porque "la orden viene de arriba".

Como ya la comunidad tenía a su favor un logro con frenar una acción directa con los paramilitares, comenzaron a cuestionarse por qué los grupos armados para cualquier asesinato justificaban que "la orden viene de arriba" y comenzaron a insistir para que dijeran de donde 
arriba o de arriba ¿de qué? Y de esta manera se fue creando la fuerza para enfrentar y echar manos de la paz, defender el territorio y la vida, desde sus escasas herramientas y posibilidades.

Se reúnen entonces los líderes del corregimiento a analizar la situación con los grupos armados legales e ilegales, sus comportamientos, atropellos y su participación en la vida comunitaria, política y económica en el territorio. Pero con la salvedad de que para estos líderes la batuta ahora tenía que pasar al pueblo, a la gente. Surge entonces la idea de generar un consenso entre líderes de todas las veredas y realizar un manifiesto o pacto de convivencia para que ellos pudieran vivir en paz, inclusive con los grupos armados y entre ellos.

Proponen realizar una convocatoria abierta para todo el corregimiento y las veredas aledañas, congregando 70 personas lideres alrededor de un sancocho y con la única finalidad de proponer unos puntos de acuerdo para realizarle la exigencia a los grupos armados de que paren la violencia, la confrontación y los asesinatos, que ellos querían vivir en paz.

Se realizaron entonces 3 grupos de trabajo, cada uno sacó 10 puntos para luego ser sintetizados en el acuerdo final, precisamente de 10 puntos que recogían el sentir de todos los pobladores y que servirían de inicio para un pulso de negociación entre la comunidad y los grupos armados que hacen presencia en el territorio.

Los puntos fueron los siguientes:

1. Ningún grupo armado podrá quitarle la vida a cualquier persona de la comunidad ya sea culpable o inocente.

2. Ninguna persona o grupo armado podrá expender, ni consumir sustancias alucinógenas dentro del territorio.

3. Ninguna persona o grupo armado podrá prohibir la libre movilidad de las comunidades.

4. Toda persona que viole sexualmente o se compruebe que cometió un acto sexual abusivo contra un miembro de la comunidad será entregado a la autoridad competente.

5. Exigimos respeto a las decisiones de la comunidad en temas como:

- Sanción a peleas y riñas entre ciudadanos

- Robos

- Calumnias, injurias y chismes callejeros

- Comportamientos inmorales que busquen provocación o desprestigio en nuestros jóvenes

- Otros que se presenten en el vivir cotidiano de nuestras comunidades y que puedan ser de la competencia de las organizaciones sociales de nuestro territorio 
6. Ningún grupo armado podrá acampar ni enfrentar a su enemigo dentro de la población civil ni mucho menos utilizarla como escudo humano.

7. El cuidado del medio ambiente y la prevención de acciones que le ocasionen daño, será responsabilidad de la comunidad y de todo aquel que circule por este territorio.

8. Ningún grupo armado se debe oponer a que la comunidad auxilie heridos y les dé cristiana sepultura a sus muertos.

9. Exigimos respeto a las autoridades civiles, las organizaciones comunitarias y de derechos humanos, el respeto a la libre organización y el respeto a la vida de los líderes comunitarios.

10. Para una sana convivencia, la seguridad y la paz, exigimos no más minas antipersona y no más reclutamientos forzados.

La comunidad los denomino "normas para la convivencia pacífica en el territorio" y fueron presentados a los grupos armados, quienes dieron respuesta:

Las FARC-EP dijeron que ellos apoyaban y respetan lo que la comunidad decidiera y propusiera, puesto que ellos estaban en un proceso de paz y esto se enmarcaba dentro de los fines del mismo; sólo tenían un problema con el punto 4 acerca de los violadores porque si ellos lo detenían antes que la comunidad aplicarían su propia ley en estos casos y en el tema de las minas antipersona porque es su única manera de detener el avance de las tropas enemigas, sin embargo avisarían a la comunidad la ubicación de las mismas.

Los grupos paramilitares presentes, luego de un pulso de negociación más fuerte y con mayor dificultad, puesto que sus decisiones requerían ser tomadas por personas en otro lugar de Colombia y esto debía pasar por varios días, también cedieron, pero se opusieron al punto 8 con el argumento de que ellos tenían que cumplir siempre con los ajusticiamientos y debían rematar si era necesario; a lo cual la comunidad se remitió al DIH y les exigió que respetaran esta posición. Su respuesta fue entonces que ellos les comunicarían a sus jefes y ellos tomarán la decisión. Con la guerrilla del ELN nunca se presentó negociación directa.

Luego de este pulso de negociación, la comunidad presentó la idea de realizar un acto simbólico que sellara con toda la comunidad el pacto realizado en cabeza de estos líderes y el apoyo de sus comunidades. Fue allí donde promovieron el "primer encuentro por la paz y la reconciliación del corregimiento de Puerto López", donde congregaron personas de todas las veredas, alrededor de 5000 personas en una multitudinaria marcha por la carretera que comunica al corregimiento con el municipio de El Bagre. Todos iban vestidos de blanco y con mensajes directos a los grupos armados exigiendo, sin miedo, respeto a la vida y a la organización social. Exigiendo el respeto a los campesinos y campesinas y a la construcción de tejido social. 
Foto 5: Marcha por la Paz, proceso propio, autónomo de las comunidades de la región.

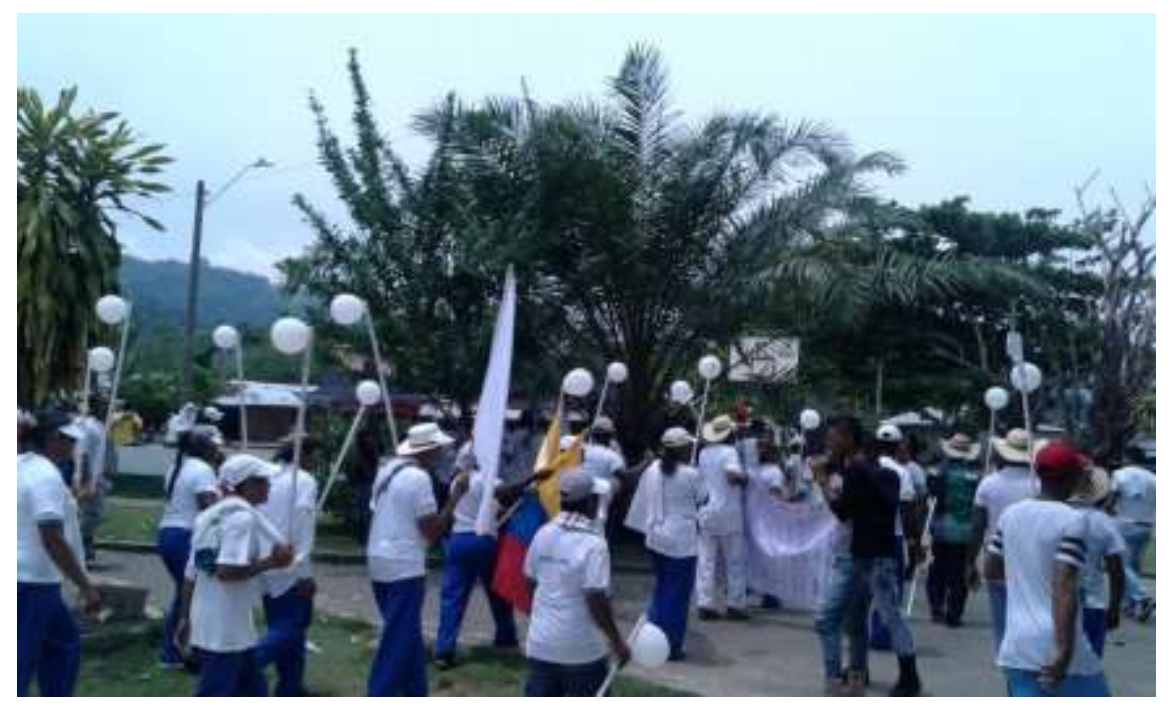

Fuente: Archivo del proceso.

La marcha terminó en el parque principal del corregimiento, sitio que antes servía de lugar de confinamiento donde los paramilitares asesinaban de manera selectiva y frente a la comunidad, donde gritaban órdenes de muerte y despojo a los campesinos. Y allí la comunidad se reunía para firmar un pacto cargado de exigencias a los grupos armados. Se realizaron actividades culturales, artísticas con presencia de manifestaciones populares y movimientos sociales presentes en el territorio; luego, se pasó a firmar un cartel donde se visualizaban todos los puntos o normas de convivencia. Toda la comunidad firmó este cartel, las organizaciones y en el centro de la plaza del pueblo quedó plasmado el grito de construcción de paz desde el territorio para luego ser presentado a los grupos armados y hacer efectivo su cumplimiento.

Desde el día de la marcha y hasta finalizar el 2015, a pesar de no recibir respuestas directas sobre algunos temas puntuales del manifiesto de la comunidad, no se presentaron más desplazamientos, ni confinamientos, y en términos generales los puntos sirvieron de guía a la comunidad para establecer un nuevo tipo de relacionamiento con los actores armados y el conflicto.

La veeduría de estos acuerdos de convivencia para la paz la asumió la comunidad, con sus propios recursos y métodos, trasladando estos a sus propias realidades o modos de vida en medio del conflicto, con aplicaciones efectivas y no abstractas como en ocasiones lo plantean las normas internacionales.

Tenemos entonces, un hito en la historia de Colombia; pero también un hito en la negociación de paz entre las insurgencias y el Estado, porque mientras en todo el país hablan del pueblo y de cada lado lo reclaman, este mismo se levanta y construye sin pedir permiso, ni favores, su propio modelo de paz desde los territorios, reconociendo su realidad y sus necesidades. Así, entendemos 
que sólo construcciones populares desde las particularidades del territorio, que resistan organizadamente al modelo económico y militar que trata de someterlos a dinámicas que generan más pauperización de las comunidades, puede aportar a la construcción de otra Colombia, otra economía, otra sociedad.

La apropiación de estos procesos de resistencia y construcción popular puede servir de ejemplo para otros territorios golpeados por la violencia, y quitarle el velo del miedo a los procesos sociales para soñar en construir un país diferente.

A pesar de esta situación, en los últimos días del año 2015, el corregimiento de Puerto López viene padeciendo el recrudecimiento del conflicto por el reacomodo de fuerzas de los actores armados y de los poderes económicos que quieren obtener los recursos de la extracción minera y de la hoja de coca. Se están presentando enfrentamientos y movimientos de tropas de todos los actores legales e ilegales del conflicto armado, generando miedo y zozobra en los pobladores a solo meses de la inminente desaparición de las FARC-EP como grupo armado quedando estos territorios a merced de otros poderes, sumado a la incapacidad, inoperancia y, en casos, complicidad de todo el aparato estatal.

En el futuro cercano de estos pobladores del corregimiento Puerto López, puede entonces plantearse dos escenarios, se solidifican como proceso social en resistencia a la violencia histórica, cueste lo que cueste o definitivamente están destinados a pasar de mano en mano de los actores armados con la mirada displicente y cómplice del Estado Colombiano y de todos nosotros.

\section{Conclusiones.}

El proceso formativo se desarrolló sobre la base de los debates sobre el contexto.

Exploramos conceptos tales como el de democracia en el que interactuaron diferencias en género, edad, profesión, posición política, ideológica, religiosa, etnicidad, etc. Concluimos que "estas posiciones y visiones de la realidad tienen un papel fundamental en la construcción de conocimiento y es el de darnos otra mirada a la misma situación. Por tanto, la diferencia nos complementa, más que violentarnos, la opinión del otro/a no es solo para escucharla, sino también para analizar y debatir, no para convencer a nadie, sino para construir con el otro. Cada quien aporta de acuerdo a sus posibilidades e intereses".

Gracias a que se compartió dentro de la escuela con víctimas de la violencia con todo lo que psicosocialmente esto implica; una mujer trans desplazada de la masacre de la vereda El Aro, municipio de Ituango, con cuatro hermanos asesinados, uno de ellos por su homosexualidad y ella con una larga historia de discriminación y violencia, las comunidades indígenas, que han sido "constantemente humillados por las administraciones municipales" al calificarlos de "vividores" y los demás participantes de las escuelas con sus historias particulares en medio de un contexto permanentemente violento, intolerante, individualista, todos ellos hablando desde el 
sentimiento, cosa que contrastó inicialmente, con los profesionales (funcionarios públicos) que hablaban desde la institución y las instancias que ésta propicia para la participación, pero de una manera muy racionalizada, posición que se logró, fueran cambiando en el avance de la escuela.

Los funcionarios, con el desarrollo de la escuela, fueron asumiendo que su papel en esta, era de aportar al grupo desde sus conocimientos como profesionales y compartir sus historias de vida y de las personas que ellos atienden en sus oficinas, entendieron que el problema no es sólo la aplicación de la norma, sino también entender cuál es la necesidad sentida del que está al otro lado del escritorio.

Todo lo anterior generó cohesión de grupo, vinculando las diferencias culturales y sociales, alejándose de los estigmas de los que hablamos en la conformación del grupo.

La metodología permitió que el papel de los participantes fuera protagonista en la construcción de la realidad, las reflexiones históricas y teóricas, que plasmarán sus realidades políticas, sociales y territoriales concretas; con ello sentían que podían lograr transformaciones reales desde su interior, sus organizaciones y sus veredas.

Cada facilitador proponía técnicas donde lo principal era la integración de todos en la construcción de los contenidos y la dinámica de cada sesión, indiferente del nivel académico y función dentro del municipio, ya fuera funcionario o líder social, lo que llevaba a dejar las diferencias que podía haber entre los mismos por fuera del aula.

Todos tenían algo que aportar a la construcción de la sesión, todo el tiempo fue un encuentro entre iguales.

Dentro de la dinámica se contaban historias personales, ideas, lo que permitió sensibilizarnos frente a la condición del otro, sus sueños, sus dolores, sus angustias etc., como lo expresaban dos funcionarios, "la escuela de DDHH nos hizo más humanos".

Este tipo de escenarios formativos que ponen por sobre el saber instituido que genera incluso exclusión, es necesario anteponer la lógica del encuentro, del reconocimiento, del lenguaje cercano para que el sentimiento sea el que se mueva y nos permita reconocernos como iguales, como afectados, como necesitados del otro.

Este ejercicio formativo por sobre todo nos permitió darnos cuenta, de nuestra realidad, una dura y difícil realidad, y con ella construir juntos y juntas, alternativas viables, y empujar entre toda la ejecución real de dichas decisiones colectivas, así, construir entre todos y todas, una visión conjunta de territorio, de proyecto, de luchas por la vida digna.

Es prioritario darles continuidad a estos procesos, alimentarlos, siempre desde la lógica desde abajo, desde la diversidad de saberes, desde el reconocimiento y la capacidad creativa local. 


\section{Bibliografía.}

Balbin Alvarez, J. W., Insuasty Rodriguez, A., Cadavid Acevedo, P., \& Restrepo Marìn, L. P. (2009). Victimas, violencia y despojo. Medellìn: Litoimpacto. Obtenido de http://web.usbmed.edu.co/usbmed/formacion/docs/victimas.pdf

Botero Fernandez, L. (12 de julio de 2016). El Bagre, epicentro de ataques a defensores de derechos humanos. Obtenido de El Espectador: http://www.elespectador.com/noticias/nacional/antioquia/el-bagre-epicentro-deataques-defensores-de-derechos-hu-articulo-642820

Comunidad Bajo Cauca. (2015). Entrevista 1. El juntarnos no permite volver a soñar. Bajo Cauca, Antioquia, Colombia: Archivo propio.

Comunidad Bajo Cauca. (2015). Entrevista 2. Economia de la región. Bajo cauca, Antioquia, Bajo Cauca: Archivo propio.

Comunidad Bajo Cauca. (2015). Entrevista 3. Apuestas de pazy negociacion desde abajo. Bajo Cauca, Antioquia, Colombia: Archivo personal.

Escuela de derechos humanos y ciudadanìa. (2015). Serie de Mediadores pedagògicos. Cuadernillo guia. Bajo Cauca, Antioquia, Colombia: Escuela de Derechos Humanos y ciudadanì.

Fals Borda, O., \& Rodriguez, B. C. (1987). Investigaciòn participativa. Montevideo: La Banda Oriental.

Ghiso, A. (1999). "De la práctica singular al diálogo con lo plural. Aproximaciones a otros tránsitos y sentidos de la sistematización en épocas de globalización”. La Piragua, 5-12.

Ghiso, A. (2001). Sistematizacion de experiencias en Educacion popular. Memorias. foro: los contextos actuales de la Educacion Popular. Medellin, Antioquia, Colombia: Fe y alegrìa.

Ghiso, A. M. (2016). Profesionalización de pedagogos sociales en latinoamerica. Otra lectura a los tránsitos entre la educación popular y la pedagogía social. El Ágora USB, 16(1), 6375. Obtenido de http://revistas.usb.edu.co/index.php/Agora/article/view/2165/1893

Instituto Popular de Capacitacion. (27 de septiembre de 2012). BACRIM en el Bajo Cauca: un pacto débil y parcial. Obtenido de colectivodeabogados: http://www.colectivodeabogados.org/BACRIM-en-el-Bajo-Cauca-un-pacto

Instituto Popular de Capacitacion. (2014). Informe del Observatorio de derechos humanos. Medellìn: IPC.

Instituto Popular de Capacitación. (15 de septiembre de 2015). Situación de DDHH en Bajo Cauca, Urabá y Suroeste de Antioquia tiende a complicarse. Obtenido de Verdad abierta: http://www.verdadabierta.com/desde-regiones/5968-situacion-de-ddhh-en-bajocauca-uraba-y-suroeste-de-antioquia-tiende-a-complicarse

Reyes, A. (enero de 2009). La sistematización de experiencias y la vision emergente en el hecho educativo. Interface: a journal for and about social movements, 1(1), 179 - 187 . Obtenido de http://www.interfacejournal.net/wordpress/wp-content/uploads/2010/11/interfaceissue-1-1-pp179-187-Reyes.pdf

Ruiz Botero, L. D. (2002). La sistematizacion de pràcticas. Documento para sitematizacion de estrategias educativas implementadas por el CMFS para abordar coflictos. Medellin: CMFS. 
Salcedo, L., Pinzón , R., \& Duarte, C. (9 de septiembre de 2013). El paro nacional agrario: un análisis de los actores agrarios y los procesos organizativos del campesinado Colombiano. Obtenido de Javeriana Cali: http://www.javerianacali.edu.co/sites/ujc/files/node/fielddocuments/field_document_file/el_paro_nacional_agrario-

_un_analisis_de_los_actores_agrarios_y_los_procesos_organizativos_del_campesinado _colombiano._centro_de_estudios_interculturales._pdf

Tarazá informa. (06 de febrero de 2015). Escuela de Derechos Humanos inicia clases. Obtenido de Tarazà informa: http://www.taraza-antioquia.gov.co/apcaa/view.php3?vid=1090\&cmd\%5B1090\%5D=x-1090-1845060

Torres Carrillo, A. (1998). La sistematizacion de experiencias educativas. Reflexiones sobre una practica reciente. Obtenido de Universidad Pedagógica Nacional: http://www.pedagogica.edu.co/storage/ps/articulos/pedysab13_04arti.pdf

Universidad Católica del Norte. (13 de enero de 2016). Escuela de derechos humanos y ciudadanía. Obtenido de Universidad Católica del Norte: http://www.ucn.edu.co/institucion/salaprensa/noticias/Paginas/escuela-de-derechos-humanos-y-ciudadania-edhc.aspx

Universidad Católicia del Norte. (13 de mayo de 2015). Escuela de Derechos Humanos Avanzando paso a paso en busca de la Paz. Obtenido de Universidad Católicia del Norte: http://www.ucn.edu.co/institucion/sala-prensa/noticias/Paginas/escuela-dederechos-humanos-avanzando-paso-a-paso-en-busca-de-la-paz.aspx

\section{Nota.}

' Proyecto: Escuela de DDHH y ciudadanía. Desarrollado en 8 municipios de Antioquia, durante el 2015 